\title{
Expression and Regulation of Glucose Transporters in the Bovine Mammary Gland ${ }^{1}$
}

\author{
F.-Q. Zhao ${ }^{2}$ and A. F. Keating \\ Lactation and Mammary Gland Biology Group, Department of Animal Science, University of Vermont, Burlington 05405
}

\section{ABSTRACT}

Glucose is the primary precursor for the synthesis of lactose, which controls milk volume by maintaining the osmolarity of milk. Glucose uptake in the mammary gland plays a key role in milk production. Glucose transport across the plasma membranes of mammalian cells is carried out by 2 distinct processes: facilitative transport, mediated by a family of facilitative glucose transporters (GLUT); and sodium-dependent transport, mediated by the $\mathrm{Na}^{+} /$glucose cotransporters (SGLT). Transport kinetic studies indicate that glucose transport across the plasma membrane of the lactating bovine mammary epithelial cell has a $K_{m}$ value of 8.29 $\mathrm{m} M$ for 3-O-methyl-D-glucose and can be inhibited by both cytochalasin-B and phloretin, indicating a facilitative transport process. This is consistent with the observation that in the lactating bovine mammary gland, GLUT1 is the predominant glucose transporter. However, the bovine lactating mammary gland also expresses GLUT3, GLUT4, GLUT5, GLUT8, GLUT12, and sodium-dependent SGLT1 and SGLT2 at different levels. Studies of protein expression and cellular and subcellular localizations of these transporters are needed to address their physiological functions in the mammary gland. From late pregnancy to early lactation, expression of GLUT1, GLUT8, GLUT12, SGLT1, and SGLT2 mRNA increases from at least 5-fold to several hundred-fold, suggesting that these transporters may be regulated by lactogenic hormones and have roles in milk synthesis. The GLUT1 protein is detected in lactating mammary epithelial cells. Its expression level decreases from early to late lactation stages and becomes barely detectable in the nonlactating gland. Both GLUT1 mRNA and protein levels in the lactating mammary gland are not significantly affected by exogenous bovine growth hormone, and, in addition, GLUT1 mRNA does not appear to be affected by leptin.

\footnotetext{
Received July 25, 2006.

Accepted September 8, 2006.

${ }^{1}$ Presented at the ADSA-ASAS Joint Annual Meeting, Minneapolis, MN, July 2006

${ }^{2}$ Corresponding author: fzhao@uvm.edu
}

Key words: glucose transporter, glucose uptake, lactation, mammary gland

\section{INTRODUCTION}

In lactating animals, providing glucose for the mammary gland is a metabolic priority because glucose is the primary precursor for lactose synthesis in the mammary epithelial cell. Because lactose maintains the osmolarity of milk, the rate of lactose synthesis serves as a major factor influencing milk volume (Neville et al., 1983; Cant et al., 2002). In addition to its importance as the precursor for lactose synthesis, glucose is also used for the generation of ATP and the cofactor nicotimamide dinucleotide phosphate and is used as a substrate for protein, lipid, and nucleotide synthesis. The mammary gland itself cannot synthesize glucose from other precursors because of the lack of glucose-6-phosphatase (Scott et al., 1976; Threadgold and Kuhn, 1979). Therefore, the mammary gland is dependent on the blood supply for its glucose needs. In a lactating cow, $72 \mathrm{~g}$ of glucose is required to produce $1 \mathrm{~kg}$ of milk (Kronfeld, 1982). Therefore, in a cow producing $40 \mathrm{~kg}$ of milk per day the mammary gland is required to take up about $3 \mathrm{~kg}$ of glucose daily. Indeed, mammary gland uptake can account for as much as 60 to $85 \%$ of the total glucose that enters the blood (Annison and Linzell, 1964; Chaiyabutr et al., 1980; Sunehag et al., 2002, 2003).

Direct and indirect techniques demonstrate that a steep glucose concentration gradient exists across the basal plasma membrane of mammary epithelial cells, from 2.0 to $5.0 \mathrm{~m} M$ in plasma to 0.1 to $0.5 \mathrm{~m} M$ in the cell (Faulkner et al., 1981; Cherepanov et al., 2000). The intracellular glucose concentration is significantly lower than the $K_{m}$ for the rate-limiting enzyme in lactose synthesis, lactose synthase (Faulkner and Peaker, 1987). Therefore, glucose transport across the plasma membrane may be a rate-limiting step in milk synthesis, and several observations support this theory. Lactose synthesis and milk yield show a linear or positive correlation with glucose uptake in the mammary gland of goats and cows (Kronfeld, 1982; Nielsen and Jakobsen, 1993; Hurtaud et al., 2000; Kim et al., 2001; Niel- 
sen et al., 2001; Cant et al., 2002; Huhtanen et al., 2002). The galactopoietic effect elicited by exogenous bovine growth hormone $(\mathbf{G H})$ requires increased glucose uptake by mammary cells (Davis et al., 1988; Mepham et al., 1990; Faulkner, 1999). Milk lactose synthesis and milk yield decrease in cows treated with phlorizin, a potent inhibitor of intestinal glucose absorption and renal glucose reabsorption by inhibiting the $\mathrm{Na}^{+} / \mathrm{D}$-glucose cotransporter (Bradford and Allen, 2005). Regulation of glucose transport in the bovine mammary gland as well as in other tissues also serves a key role in maintaining glucose homeostasis during lactation (for reviews, see Bell, 1995; Bell and Bauman, 1997).

\section{GLUCOSE TRANSPORT AND GLUCOSE TRANSPORTERS IN MAMMALIAN CELLS}

The plasma membranes of virtually all mammalian cells possess one or more transport systems to allow glucose movement either into or out of the cells. In mammals, blood glucose levels are maintained within a narrow range by homeostatic mechanisms, and most cells take up glucose by a passive, facilitative transport process, driven by the downward glucose concentration gradient across the plasma membrane (Widdas, 1988). This facilitative transport is inhibitable by cytochalasin-B or phloretin. It is believed that only in the epithelial cell brush border of the small intestine and the kidney proximal convoluted tubules is glucose absorbed or reabsorbed by an active mechanism that uses the downward sodium concentration gradient to transport glucose against its electrochemical gradient. This sodium-dependent transport can be inhibited by phlorizin. The facilitative and sodium-dependent glucose transport systems are mediated by 2 distinct families of glucose transporters (Table 1).

\section{Facilitative Glucose Transporters}

Saturable, stereoselective, bidirectional, and energyindependent facilitated diffusion is mediated by the facilitative glucose transporters (solute carriers SLC2A, protein symbol GLUT). Thus far, 13 functional facilitative glucose transporter isoforms have been cloned, characterized and designated as GLUT1-GLUT12 (based on the chronological order of publication) and $\mathrm{H}^{+} /$myo-inositol cotransporter (HMIT). A genomic-wide GenBank search indicated that these 13 isoforms may represent all facilitative glucose transporter members in humans (Joost and Thorens, 2001). These transporters are structurally conserved and related, consisting of 12 transmembrane domains with both the aminoand carboxy-terminals located in the cytoplasm, and an N-glycosylation site located on either the first or ninth extracellular loop. The known kinetic properties, major sites of expression, and proposed function of each of these transporters in human and rodent tissues are summarized in Table 1. Their tissue-specific distribution, distinct kinetic properties, and differential regulation by ambient glucose and hormones, especially insulin, reveal that each transporter isoform plays a specific role in glucose uptake in various tissues and in glucose homeostasis (Wood and Trayhurn, 2003).

The glucose transporters GLUT1 to GLUT5 have been extensively studied. GLUT1 has been ubiquitously detected in cells and tissues, including the mammary gland (Madon et al., 1990; Burant et al., 1991; Zhao et al., 1999). In many tissues in which it is expressed, GLUT1 is concentrated in the cells of blood-tissue barriers (Cornford et al., 1994). Because of the ubiquitous distribution and cellular localization, GLUT1 is considered to be the primary transporter responsible for basal glucose uptake. GLUT2 is involved in the release of hepatic glucose, in the release of absorbed and reabsorbed glucose in the small intestine and kidney, respectively, and in the regulation of insulin secretion from $\beta$-cells. GLUT3 plays a major role as the brain neuronal glucose transporter. GLUT4 mediates insulinstimulated glucose uptake in skeletal muscle and adipose tissues (Holman and Sandoval, 2001). GLUT5 may participate in the uptake of dietary fructose from the lumen of the small intestine.

GLUT6 to GLUT12 and HMIT are the most recently cloned facilitative glucose transporter isoforms and have been characterized to a lesser extent. GLUT6 mRNA is primarily expressed in the spleen, peripheral leukocytes, and brain (Doege et al., 2000a), but its activity is still unclear. GLUT7 was cloned from human small intestinal tissue and was also found to be expressed in the colon, testis, and prostate (Li et al., 2004); it transports both glucose and fructose with high affinity (Li et al., 2004). GLUT8 is postulated to be another insulin-regulated glucose transporter because it was found to be responsible for insulin-stimulated glucose uptake in the blastocyst (Carayannopoulos et al., 2000). It may also be involved in providing glucose for DNA synthesis in male germ cells because it is highly expressed in the testis, and this expression is markedly inhibited by estrogen treatment (Doege et al., 2000b). GLUT9 is found primarily in the kidney and liver (Phay et al., 2000). GLUT10 has the highest levels of expression in the liver and pancreas (McVie-Wylie et al., 2001), and because human GLUT10 is localized to chromosome 20q12-q13.1, one of the genomic loci associated with non-insulin-dependent diabetes mellitus, it may be a candidate for a susceptibility marker for non-insulin-dependent diabetes mellitus. Multiple GLUT11 tis- 
Table 1. Summary of the properties of facilitative glucose transporter and $\mathrm{Na}^{+} /$glucose cotransporter family members

\begin{tabular}{|c|c|c|c|c|}
\hline Protein $^{1}$ & $\begin{array}{l}\text { Major } \\
\text { isoform, } \\
\text { AA }\end{array}$ & $\begin{array}{l}K_{m}{ }^{2} \\
\mathrm{~m} M\end{array}$ & Major sites of expression & Proposed function \\
\hline GLUT1 (Mueckler et al., 1985) & 492 & 6.9 & $\begin{array}{l}\text { Ubiquitous distribution in tissues } \\
\text { and culture cells }\end{array}$ & $\begin{array}{l}\text { Basal glucose uptake; transport across } \\
\text { blood-tissue barriers }\end{array}$ \\
\hline GLUT2 (Fukumoto et al., 1988) & 524 & 16.2 & $\begin{array}{l}\text { Liver, islets, kidney, small } \\
\text { intestine }\end{array}$ & High-capacity low-affinity transport \\
\hline GLUT3 (Kayano et al., 1988) & 496 & 1.8 & Brain and nerve cells & Neuronal transport \\
\hline GLUT4 (Fukumoto et al., 1989) & 509 & 4.6 & Muscle, fat, heart & $\begin{array}{l}\text { Insulin-regulated transport in muscle } \\
\text { and fat }\end{array}$ \\
\hline GLUT6 (Doege et al., 2000a) & 507 & 5 & Spleen, leukocytes, brain & \\
\hline GLUT7 (Li et al., 2004) & 524 & 0.3 & Small intestine, colon, testis & Transport of fructose \\
\hline $\begin{array}{l}\text { GLUT8 (Carayannopoulos et al., 2000; } \\
\text { Doege et al., 2000b) }\end{array}$ & 477 & 2.4 & $\begin{array}{l}\text { Testis, blastocyst, brain, muscle, } \\
\text { adipocytes }\end{array}$ & $\begin{array}{l}\text { Fuel supply of mature spermatozoa; } \\
\text { insulin-responsive transport in } \\
\text { blastocyst }\end{array}$ \\
\hline GLUT9 (Phay et al., 2000) & $511 / 540$ & $?$ & Liver, kidney & \\
\hline GLUT10 (McVie-Wylie et al., 2001) & 541 & 0.3 & Liver, pancreas & \\
\hline SGLT2 (Wells et al., 1992) & 672 & 10 & Kidney & $\begin{array}{l}\text { Los affinity and high selectivity for } \\
\text { glucose }\end{array}$ \\
\hline SGLT3 (Kong et al., 1993) & 660 & 2 & Small intestine, skeletal muscle & Glucose activated $\mathrm{Na}^{+}$channel \\
\hline
\end{tabular}

${ }^{1}$ Pertinent references are shown in parentheses.

${ }^{2}$ Net influx for 2-deoxyglucose.

${ }^{3} ?=$ Unknown.

sue-specific splicing variants have been reported to be expressed in a number of tissues, but most abundantly in the skeletal muscle and heart (Wu et al., 2002). GLUT12 was originally cloned from breast cancer cells (Rogers et al., 2002), and its expression has been found in the heart, skeletal muscle, brown adipose tissue, prostate, and mammary glands of both pregnant and lactating rats. Finally, HMIT is expressed predominantly in the brain with specific transport activity for myo-inositol (Uldry et al., 2001).

\section{$\mathrm{Na}^{+} /$Glucose Cotransporters}

The second family, the sodium-dependent glucose transporters, or $\mathrm{Na}^{+} /$glucose cotransporters (solute carriers SLC5A, protein symbol SGLT), mediate the active, sodium-linked glucose transport process. Concordant with this active transport function, the $\mathrm{Na}^{+} /$glucose cotransporters are mainly located in the brush-border membranes of epithelial cells in the small intestine and the proximal convoluted tubule of the kidney (Wright and Turk, 2004). Wright and coworkers isolated the first cDNA clone encoding a protein exhibiting all the properties of the small intestinal brush-border transporter and designated it SGLT1 (Hediger et al., 1987). Since the cloning of SGLT1, other isoforms of SGLT genes have been discovered, including SGLT2 (Wells et al., 1992), SGLT3 (Kong et al., 1993), and at least 6 SGLT-related orphan cDNA (Pajor and Wright, 1992; Wright, 2001). These proteins contain several characteristic and conserved sodium:solute symporter family signatures and have 14 transmembrane domains. It is now believed that SGLT1 is largely responsible for glucose and galactose transport across the intestinal brush border, and that it plays only a minor role, perhaps in the distal tubule, in glucose reabsorption in the kidney. Glucose transport in the proximal tubule of the kidney is mainly attributed to SGLT2, which has a low affinity for sugars and a high selectivity for glucose over galactose. The function and transport activity of other $\mathrm{Na}^{+} /$glucose cotransporters remain as yet unclear.

\section{BOVINE GLUCOSE TRANSPORTERS}

To our knowledge, the full-length cDNA sequences of bovine glucose transporters that have been reported thus far are GLUT1 (GenBank accession \#NM_174602), GLUT3 (NM_174603), GLUT4 (NM_174604), GLUT8 (AY208940), GLUT12 (AY514443), SGLT1 (AF508807), SGLT2 (AY208941), and SGLT5 (AY514442). Here we summarize our current knowledge about some of these transporters, which are mostly relevant to glucose transport in the bovine mammary gland. 


\section{GLUT1}

Bovine GLUT1 (bGLUT1), deduced from its fulllength cDNA (Boado and Pardridge, 1990), contains $492 \mathrm{AA}$ with a predicted molecular weight of $54 \mathrm{kDa}$. However, in PAGE, both the in vitro transcription/ translation product of the full-length bGLUT1 cDNA (Zhao et al., 2004) and the protein bands detected in bovine tissues by Western blot using an anti-GLUT1 antibody (Boado and Pardridge, 1990; Zhao et al., 1996a) show the molecular weight to be around $40 \mathrm{kDa}$. The reason for this discrepancy is uncertain, and it is possible that this may be due to some form of posttranslational modification. The deduced bGLUT1 AA sequence is highly conservative and exhibits approximately 96 to $98 \%$ sequence identity to the human, rat, and mouse GLUT1. However, there is a unique prolinerich sequence between the putative first 2 transmembrane domains, just close to the predicted N-glycosylation site at $\mathrm{Asn}^{45}$ of bovine bGLUT1 (Boado and Pardridge, 1990). The significance of this structure is not known. A search of the current GenBank bovine genomic database indicates that bGLUT1 is a single-copy gene located on chromosome 11 . The gene consists of 10 exons as in the human and extends over $28 \mathrm{~kb}$. The bGLUT1 can be glycosylated (Zhao et al., 2004), which has been shown to be critical for the transport activity for GLUT (Asano et al., 1991), and may explain the doublet bands for GLUT1 proteins observed in bovine tissues (Boado and Pardridge, 1990; Zhao et al., 1996a).

The GLUT1 mRNA is ubiquitously expressed in lactating bovine tissues, being most abundant in the mammary gland and kidney and lowest in the omental fat and skeletal muscle, with a single transcript of $2.8 \mathrm{~kb}$ (Zhao et al., 1993). It is also expressed in fetal bovine tissues (Hocquette et al., 2006) and the bovine follicle and corpus luteum (Nishimoto et al., 2006). Protein levels of GLUT1 are significantly higher in glycolytic than in oxidative muscles (Duhlmeier et al., 2005). In the brain, bGLUT1 mRNA is specifically expressed only in the blood-brain barrier (Boado and Pardridge, 1990). During postnatal development, GLUT1 protein levels are unchanged in the bovine skeletal muscle, adipose tissue, and brain (Abe et al., 2001). However, GLUT1 expression in adipose tissue is dramatically changed during different stages of lactation, from very low levels in early lactation to relatively strong levels in late and nonlactating stages (Komatsu et al., 2005).

Regulation of GLUT1 expression has been studied extensively in vitro. In general, GLUT1 expression is induced by many growth stimuli to meet the increased energy and biosynthetic demand of dividing cells. For example, in bovine chromaffin cells, GLUT1 mRNA is elevated by glucose deprivation and IGF-I activation
(Fladeby et al., 2003). Evidence indicates that the bGLUT1 gene may also be regulated at the translational and posttranslational levels (Boado and Pardridge, 1990; Boado, 2000).

\section{GLUT4}

The full-length bovine GLUT4 (bGLUT4) cDNA is $2,656 \mathrm{bp}$ and is predicted to encode a protein of $509 \mathrm{AA}$, with a molecular weight of approximately $55 \mathrm{kDa}$ (Abe et al., 1997). Bovine GLUT4 is 65\% identical to bGLUT1 and is highly conserved with human and rodent GLUT4, with a possible N-linked glycosylation site at $\mathrm{Asn}^{57}$ located between the putative first 2 transmembrane domains. The GLUT4 protein may be subject to differential glycosylation in bovine adipose tissue, heart, and skeletal muscle (Hocquette et al., 1997). The single-copy bGLUT4 gene is located on chromosome 19 and consists of 11 exons and 10 introns, but extends over only $5.4 \mathrm{~kb}$.

In the bovine, GLUT4 mRNA expression is mainly confined to the insulin-sensitive tissues, such as the skeletal muscle, heart, and adipose tissue, essentially the same as in human tissues (Zhao et al., 1993; Abe et al., 1997), suggesting a role in insulin regulation of glucose uptake in these tissues, as occurs in other species. Interestingly, GLUT4 is also expressed in preimplantation embryos (Navarrete Santos et al., 2000). In fetal bovine perirenal adipose tissue, GLUT4 protein levels markedly increase during fetal development, reach maximal expression at 6 to $8 \mathrm{mo}$ of age, and sharply decrease thereafter, with a simultaneous increase in the GLUT1 protein level (Hocquette et al., 2006). During postnatal development, GLUT4 levels in the skeletal muscle and subcutaneous adipose tissue decrease gradually, and at 12 mo old, GLUT4 levels are only $40 \%$ of those seen at birth (Abe et al., 2001). In growing calves, GLUT4 protein levels are higher in omental fat than in subcutaneous adipose tissues (Hocquette et al., 1997). In contrast to GLUT1 expression and rodent GLUT4 expression, bGLUT4 protein levels are significantly higher in oxidative than in glycolytic muscles (Hocquette et al., 1995; Duhlmeier et al., 2005). In addition, GLUT4 mRNA expression in bovine adipose tissue and skeletal muscle does not seem to vary with the stage of lactation (Komatsu et al., 2005).

GLUT4 has been extensively studied in humans and rodents because of its key role in the regulation of glucose homeostasis by insulin. The GLUT4 protein is located in an intracellular compartment without insulin stimulation. However, in response to insulin stimulation, GLUT4 is translocated to the plasma membrane, resulting in increased glucose uptake in muscle and adipose tissues (Watson et al., 2004; Watson and Pes- 
sin, 2006). In bovine muscle, the insulin-induced GLUT4 translocation to the plasma membrane is significantly lower than in porcine muscle, which may explain the lower insulin sensitivity in adult ruminants compared with monogastric omnivores (Duhlmeier et al., 2005). It has been speculated that the replacement of $\mathrm{Asn}^{508}$ in the C-terminus of human and rodent GLUT4 by $\mathrm{His}^{508}$ in bGLUT4 may contribute to the impaired insulin stimulation of translocation (Abe et al., 1997).

In the lactating cow, GLUT4 expression in the skeletal muscle and omental fat is dramatically reduced by administering $\mathrm{GH}$ and GH-releasing factor (GHRF), consistent with the regulation of nutrient partitioning by these hormones to shift more glucose from these tissues to the mammary gland for the purpose of increased milk synthesis (Zhao et al., 1996b).

\section{GLUT8}

The full-length bovine GLUT8 (bGLUT8) cDNA is composed of 2,073 bp and encodes for a 478-AA protein with a molecular weight of $51 \mathrm{kDa}$ (Zhao et al., 2004). The deduced bGLUT8 protein is only 26 and $24 \%$ identical to bGLUT1 and bGLUT4, respectively, but is 90 and $84 \%$ identical to human and mouse GLUT8. The bGLUT8 retains an N-linked glycosylation site on loop 9 and a putative dileucine internalization motif. The glycosylation of bGLUT8 was confirmed by the increased molecular weight of an in vitro transcription/ translation product of bGLUT8 cDNA in the presence of canine microsomal membranes (Zhao et al., 2004). The bovine genome contains a single copy of the GLUT8 gene, which is located to chromosome 11 as GLUT1 and consists of 10 exons spanning $9 \mathrm{~kb}$. A 2.1-kb bGLUT8 transcript is predominantly expressed in the testes, as in other species, but is also expressed in all other tissues examined, including the mammary gland, kidney, lung, spleen, intestine epithelia, skeletal muscle, and liver (Zhao et al., 2004).

\section{GLUT12}

Bovine GLUT12 (bGLUT12) cDNA has recently been cloned. The bGLUT12 gene is located to a single locus on chromosome 9 and consists of 5 exons ranging from 123 to $1,341 \mathrm{bp}$ and 4 introns ranging from 4,011 to $10,797 \mathrm{bp}$. The gene spans $36 \mathrm{~kb}$ (Miller et al., 2005) and is transcribed to a 2,423-bp full-length mature mRNA, predicted to encode a protein of $621 \mathrm{AA}$ with a molecular weight of $67 \mathrm{kDa}$ (Miller et al., 2005). The deduced AA sequence of bGLUT12 is 87 and $82 \%$ identical to human and mouse GLUT12 and only 20, 20, and $21 \%$ identical to bGLUT1, bGLUT4, and bGLUT8, respectively. The
bGLUT12 can also be glycosylated (Miller et al., 2005). The bGLUT12 mRNA transcript is ubiquitously expressed in bovine tissues, being most abundant in the spleen and skeletal muscle, at intermediate levels in the kidney, testes, and mammary gland, and at lower levels in the liver, lungs, and intestine (Miller et al., 2005). This tissue distribution pattern is different from the insulin-sensitive tissue-restricted expression of GLUT12 in the human (Rogers et al., 2002).

\section{SGLT1 and SGLT2}

Although both SGLT1 and SGLT2 were cloned more than a decade ago and have been well characterized in human and rodent species, bovine SGLT1 (bSGLT1) and SGLT2 (bSGLT2) were only recently cloned (Zhao et al., 2005a,b). Bovine SGLT1 is a 664-AA protein with a molecular weight of $73 \mathrm{kDa}$ (Zhao et al., 2005b). The 2,275-bp bSGLT2 mRNA encodes a 673-AA protein with a molecular weight similar to bSGLT1 (Zhao et al., 2005a). Both proteins are 58\% identical to each other and contain several characteristically conserved sodium:solute symporter family signatures. The bSGLT1 can be glycosylated, whereas glycosylation of bSGLT2 is unclear because the canine microsomal membranes shift the bSGLT2 protein weight only slightly (Zhao et al., 2005a). The bovine genome contains a single copy of each gene. The bSGLT1 gene is located on chromosome 17 and consists of at least 15 exons extending over at least $47 \mathrm{~kb}$. The bSGLT2 is located on chromosome 25 and consists of 14 exons that span only $9 \mathrm{~kb}$. Expression of SGLT1 mRNA is most abundant in bovine intestinal tissues, at intermediate levels in the bovine kidney, at lower levels in the bovine mammary gland, liver, and lungs, and not detectable in the bovine spleen, skeletal muscle, and testes (Zhao et al., 2005b). Interestingly, SGLT1 mRNA is strongly expressed in the rumen and omasum of lactating cows, suggesting that these tissues may be involved in glucose absorption (Zhao et al., 1998). As in other species, the SGLT2 mRNA is predominantly expressed in the bovine kidney as a $2.3-\mathrm{kb}$ transcript, and is expressed at lower levels in the bovine mammary gland, liver, lung, spleen, intestine, and skeletal muscle as a 3.0-kb transcript (Zhao et al., 2005a). Expression of $\mathrm{Na}^{+} /$glucose transporters in the mammary gland, liver, lungs, spleen, and skeletal muscle raises questions about their physiological roles in these tissues because the glucose uptake in these tissues is believed to be a facilitative process.

\section{GLUCOSE TRANSPORT AND GLUCOSE TRANSPORTERS IN THE MAMMARY GLAND}

Glucose transport into the epithelial cells of the mammary gland is specific, saturable, $\mathrm{Na}^{+}$-independent, and 
inhibitable by cytochalasin-B or phloretin in the guinea pig, rat, mouse, and cow (Amato and Loizzi, 1979; Threadgold et al., 1982; Prosser, 1988; Delaquis et al., 1993; Xiao and Cant, 2003; Xiao et al., 2004). For uptake of 3-O-methy-D-glucose in bovine mammary epithelial cells, the $K_{\mathrm{m}}$ is $8.29 \mathrm{~m} M$ and the $V_{\max }$ is $18.2 \mathrm{nmol} / \mathrm{min}$ per mg of protein (Xiao and Cant, 2003). In lactating rat mammary acini, the apparent $K_{m}$ for 2-deoxy-Dglucose is $16 \mathrm{mM}$, and the $V_{\max }$ is approximately 56 $\mathrm{nmol} / \mathrm{min}$ per $\mathrm{mg}$ of protein (Threadgold et al., 1982).

The glucose transporters in the mammary gland have primarily been reported in a few studies in the rat. Burnol et al. (1990) and Camps et al. (1994) reported that GLUT1 and GLUT4 are present in the rat mammary gland before conception. However, the expression of GLUT4 decreases progressively during pregnancy and becomes undetectable during lactation, whereas the levels of GLUT1 increase during pregnancy and peak during lactation. The pattern of GLUT1 and GLUT4 expression during the reproductive cycle reflects differences in the cellular composition of the mammary gland. Adipocytes, which express both GLUT4 and GLUT1, predominate before pregnancy, whereas epithelial cells, which express GLUT1 but not GLUT4, proliferate and become the predominant cell type during pregnancy and lactation. More recently, GLUT12 has been found in the rat mammary gland (Macheda et al., 2003). Immunofluorescence and immunoelectron studies have shown that GLUT1 is localized to the basolateral membrane and Golgi apparatus of the lactating mammary epithelium (Takata et al., 1997; Nemeth et al., 2000; Macheda et al., 2003), whereas GLUT12 targets the apical membrane (Macheda et al., 2003). Madon et al. (1990) have used quantitative Western blotting and cytochalasin-B binding studies to demonstrate that GLUT1 represents the major glucose transporter species in plasma membranes and about half of the glucose transporters in the Golgi membranes of lactating rat mammary epithelial cells. The presence of glucose transporters on Golgi vesicle membranes raises new questions with respect to the presence of pores in these membranes. Because only about half of the sites on Golgi vesicle membranes could be accounted for by GLUT1, it may indicate the existence of other glucose transporter species in the Golgi membrane.

Interestingly, GLUT2 protein is not expressed in the bovine and rat mammary gland (Burnol et al., 1990; Madon et al., 1990; Zhao et al., 1993) but is present in human breast tissue (Brown and Wahl, 1993). Neither GLUT3 nor GLUT5 is expressed in human or rat mammary tissues (Brown and Wahl, 1993; Camps et al., 1994). Surprisingly, there is also evidence for the presence of $\mathrm{Na}^{+} /$glucose cotransporters in the lactating mammary gland (Zhao et al., 1999; Shennan and Peaker, 2000).

\section{Glucose Transporters in the Bovine Mammary Gland}

In the early 1990s, when only GLUT1 to GLUT5 had been cloned, human cDNA were used in Northern blotting analyses of bovine tissues (Zhao et al., 1993), and it was demonstrated that only GLUT1 mRNA was found at high levels in the mammary gland of lactating cows. The GLUT3, GLUT4, and GLUT5 mRNA were also detected, but at very low levels in $10 \mu \mathrm{g}$ of poly $\left(\mathrm{A}^{+}\right)$RNA used. Later, the expression of the $\mathrm{Na}^{+}$/glucose cotransporter SGLT1 in the lactating bovine mammary gland was also detected (Zhao et al., 1998 and 1999). High levels of GLUT1 protein were also detected in both the lactating and involuted mammary gland, whereas GLUT4 protein expression was not detected (Zhao et al., 1996a). In addition, an anti-GLUT1 antibody strongly stained the single layer of epithelial cells of mammary alveoli (Zhao et al., 1996a).

Since then, new glucose transporters have been identified. To determine which of these novel glucose transporter isoforms (GLUT6 to GLUT12 and SGLT2 to SGLT3) were expressed in the bovine mammary gland, the GenBank databases were initially BLAST-searched using the human sequences of these isoforms to find expressed sequence tags (EST) clones derived from bovine mammary tissue. This approach allowed the identification of EST clones for GLUT8 and SGLT2 in the USDA Meat Animal Research Center (ARS) cDNA library of bovine mammary tissues (Zhao et al., 2004). The full-length cDNA of these 2 transporters were subsequently cloned and their expression confirmed in lactating bovine mammary tissue (Zhao et al., 2004; Zhao et al., 2005a).

In addition, although EST clones for GLUT12 were not found in the bovine mammary gland cDNA library, GLUT12 has been found to be highly expressed in rat mammary tissues and in the human breast cancer cell line MCF-7 (Rogers et al., 2002; Macheda et al., 2003). To examine expression of GLUT12 in the bovine mammary gland, rapid amplification of cDNA ends in lactating mammary tissue was carried out using specific bGLUT12 primers designed from GenBank EST sequences, and rapid amplification of cDNA end products were successfully obtained, confirming GLUT12 expression (Miller et al., 2005). The full-length bGLUT12 cDNA was subsequently cloned from the lactating bovine mammary gland (Miller et al., 2005). 


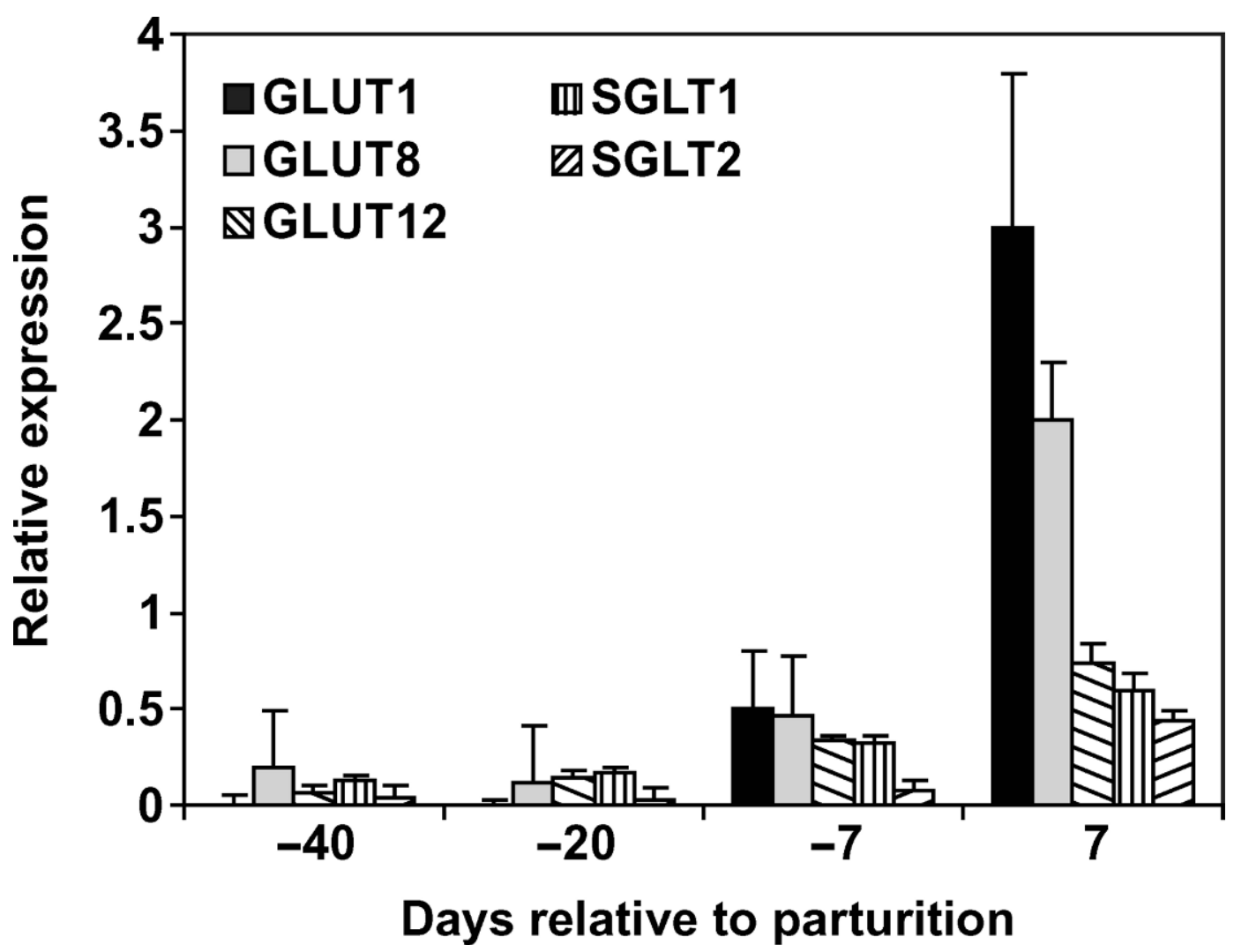

Figure 1. Quantitative reverse transcription PCR analysis of GLUT1, GLUT8, GLUT12, SGLT1, and SGLT2 mRNA expression in the bovine mammary gland at $-40,-20,-7$, and $7 \mathrm{~d}$ relative to parturition. The mammary tissues were taken by biopsy from 12 cows at each stage. The mRNA levels of each transporter were normalized to $\beta$-actin levels. Data are taken from Zhao et al. (2004, 2005a,b) and unpublished data (F.-Q. Zhao, E. H. Wall, and T. B. McFadden).

\section{REGULATION OF GLUCOSE TRANSPORTER GENE EXPRESSION IN THE BOVINE MAMMARY GLAND}

\section{Developmental Regulation}

Glucose uptake in the mammary gland is increased dramatically during lactation. To study the changes in GLUT1, GLUT8, GLUT12, SGLT1, and SGLT2 expression in the bovine mammary gland at the onset of lactation, quantitative, real-time reverse transcription PCR was used to analyze their mRNA levels in mammary tissues taken by biopsy from 12 cows at $d-40,-20,-7$, and +7 relative to calving. Expression of all transporters examined has been shown to be developmentally regulated during pregnancy and lactation, as evident from the marked increase in expression seen during the onset of lactation (Figure 1). The mRNA levels of GLUT1, GLUT8, GLUT12, SGLT1, and SGLT2 increased a few hundred-, 10-, 10-, 4-, and 10-fold, respectively, from $d-40$ to 7 . The patterns and relative expression levels among the different transporters are highly correlated both with each other and also with the begin- ning of milk synthesis. Levels of GLUT1 are barely detectable at $d-40$ and -20 ; however, in anticipation of the increased lactose synthesis requirement occurring with the onset of lactation, GLUT1 expression is greatly increased at $\mathrm{d}-7$ and is further increased approximately 6 -fold at $d 7$ when lactation is established. The expression pattern of GLUT8 mRNA is comparable to that of GLUT1; however GLUT8 levels are detectable at higher levels than GLUT1 at $d-40$ and -20 . In the same manner as GLUT1, the expression level is increased at $d-7$ and is further increased approximately 4 -fold with lactation $d 7$. These expression patterns are consistent with those detected by microarray analysis in the mouse mammary gland (Zhao et al., 2004). GLUT1 and GLUT8 have the highest levels of expression of the 5 transporters examined in Figure 1. Transporters GLUT12 and SGLT1 follow a pattern of expression similar to GLUT1 and GLUT8; however, their mRNA levels are considerably less at $d 7$. The expression pattern of SGLT2 is slightly different from those of the other transporters examined, with a smaller in- 
crease in expression at $d-7$. However, expression also increases considerably with the onset of lactation. The increase in expression during the onset of lactation indicates that all of these transporters may play specific roles to support milk synthesis. Consistent with these observations, Komatsu et al. (2005) recently reported that GLUT1 mRNA and protein are strongly expressed in the bovine mammary gland at lactation but that they are barely detectable in dry cows. However, in the same study, GLUT1 mRNA and protein abundance in the mammary gland were found unchanged at peak and late lactation. These results are contrary to our previous report that GLUT1 protein levels are significantly lower in the mammary gland at $181 \mathrm{~d}$ of lactation than at $118 \mathrm{~d}$, whereas GLUT1 mRNA levels remain unchanged (Zhao et al., 1996a). In addition, GLUT1 protein was detected with different molecular weights in lactating and dry stages, implying that GLUT1 may be subjected to differential posttranslational modifications at different stages and may then be subjected to a change in its transport kinetics (Zhao et al., 1996a).

\section{Hormonal Regulation}

A study was performed to investigate the effect of administration of GH and GHRF. Exogenous GH had no effect on either GLUT1 mRNA or protein, although milk yield increased $17 \%$. In contrast, GHRF increased milk yield (by 14\%) and GLUT1 mRNA levels (Zhao et al., 1996b). Both bovine GH and bovine GHRF dramatically decreased GLUT4 expression in peripheral adipose and muscle tissues, consistent with regulation of nutrient partitioning by these hormones to shift more glucose from these tissues to the mammary gland to support milk synthesis (Zhao et al., 1996b,c). In addition, leptin changed neither glucose uptake nor GLUT1 mRNA expression in a bovine mammary gland explant culture study (Accorsi et al., 2005).

The developmental regulation of the glucose transporters prior to and after the beginning of lactation indicates that their expression and function are likely to be regulated by lactogenic hormones around the time of lactation. Intracellular GLUT-1 concentrations in mouse mammary epithelial cells have been shown to increase approximately 15 -fold in response to prolactin and hydrocortisone (Haney, 2001). However, the regulation of glucose transporter expression in the bovine mammary gland by these hormones remains to be elucidated.

\section{CONCLUSIONS AND PERSPECTIVE}

Glucose uptake in the bovine mammary gland is of major importance for successful lactation in the dairy cow. Until recently, the majority of research carried out has been on GLUT1 in the mammary gland and GLUT4 in the adipose tissue. However, it is becoming more obvious from the identification of additional glucose transporters in the mammary gland, especially GLUT8, GLUT12, and SGLT1, that glucose uptake from the circulation into the mammary epithelial cell is a more complicated system that involves the coordination of a number of proteins. The expression of these transporters is both developmentally and hormonally regulated. Future studies are required to localize each of these transporters cellularly and subcellularly in the bovine mammary gland because their localizations may determine their physiological function. Of similar importance is determination of the transport kinetics of each transporter in the mammary gland. Adapting advanced research approaches, such as using specific gene-knockout animal models and siRNA approaches, should also provide useful information in understanding the functions of each transporter during milk synthesis. In addition, future studies to investigate the regulation of gene expression and posttranslational modifications of each transporter by lactogenic hormones will be critical. A thorough understanding of the molecular mechanisms of glucose uptake and its regulation in the mammary gland is a prerequisite for enhancing glucose utilization in the mammary gland and ultimately for improving dairy productivity and efficiency.

\section{REFERENCES}

Abe, H., Y. Kawakit, K. Hodate, and M. Saito. 2001. Postnatal development of glucose transporter proteins in bovine skeletal muscle and adipose tissue. J. Vet. Med. Sci. 63:1071-1075.

Abe, H., M. Morimatsu, H. Nikami, T. Miyashige, and M. Saito. 1997. Molecular cloning and mRNA expression of the bovine insulinresponsive glucose transporter (GLUT4). J. Anim. Sci. 75:182188.

Accorsi, P. A., M. Gamberoni, G. Isani, N. Govoni, R. Viggiani, M. Monari, M. De Ambrogi, A. Munno, C. Tamanini, and E. Seren. 2005. Leptin does not seem to influence glucose uptake by bovine mammary explants. J. Physiol. Pharmacol. 56:689-698.

Amato, P. A., and R. F. Loizzi. 1979. The effects of cytochalasin B on glucose transport and lactose synthesis in lactating mammary gland slices. Eur. J. Cell Biol. 20:150-155.

Annison, E. F., and J. L. Linzell. 1964. The oxidation and utilization of glucose and acetate by the mammary gland of the goat in relation to their overall metabolism and to milk formation. J. Physiol. 175:372-385.

Asano, T., H. Katagiri, K. Takata, J.-L. Lin, H. Ishihara, K. Inukai, K. Tsukuda, M. Kikuchi, H. Hirano, Y. Yazaki, and Y. Oka. 1991. The role of N-glycosylation of GLUT1 for glucose transport activity. J. Biol. Chem. 266:24632-24636.

Bell, A. W. 1995. Regulation of organic nutrient metabolism during transition from late pregnancy to early lactation. J. Anim. Sci. 73:2804-2819.

Bell, A. W., and D. E. Bauman. 1997. Adaptation of glucose metabolism during pregnancy and lactation. J. Mammary Gland Biol. Neoplasia 2:265-278.

Boado, R. J. 2000. Post-transcription modulation of the blood-brain barrier GLUT1 glucose transporter by brain-derived factors. J. Neural Transm. Suppl. 59:255-261. 
Boado, R. J., and W. M. Pardridge. 1990. Molecular cloning of the bovine blood-brain barrier glucose transporter cDNA and demonstration of phylogenetic conservation of the $5^{\prime}$ untranslated region. Mol. Cell. Neurosci. 1:224-232.

Bradford, B. J., and M. S. Allen. 2005. Phlorizin administration increases hepatic gluconeogenic enzyme mRNA abundance but not feed intake in late-lactation dairy cows. J. Nutr. 135:2206-2211.

Brown, R. S., and R. L. Wahl. 1993. Overexpression of GLUT1 glucose transporter in human breast cancer. Cancer 72:2979-2985.

Burant, C. F., W. I. Sivitz, H. Fukumoto, T. Kayano, S. Nagamatsu, S. Seino, J. E. Pessin, and G. I. Bell. 1991. Mammalian glucose transporters: Structure and molecular regulation. Recent Prog. Horm. Res. 47:349-387.

Burnol, A.-F., A. Leturque, M. Loizeau, C. Postic, and J. Girard. 1990. Glucose transporter expression in rat mammary gland. Biochem. J. 270:277-279.

Camps, M., S. Vilaro, X. Testar, M. Palacin, and A. Zorzano. 1994. High and polarized expression of GLUT1 glucose transporters in epithelial cells from mammary gland: Acute down-regulation of GLUT1 carriers by weaning. Endocrinology 134:924-934.

Cant, J. P., D. R. Trout, F. Qiao, and N. G. Purdie. 2002. Milk synthetic response of the bovine mammary gland to an increase in the local concentration of arterial glucose. J. Dairy Sci. 85:494-503.

Carayannopoulos, M. O., M. M.-Y. Chi, Y. Cui, J. M. Pingsterhaus, M. A. McKnight, M. Mueckler, S. U. Devaskar, and K. H. Moley. 2000. GLUT8 is a glucose transporter responsible for insulinstimulated glucose uptake in the blastocyst. Proc. Natl. Acad. Sci. USA 97:7313-7318.

Chaiyabutr, N., A. Faulkner, and M. Peaker. 1980. The utilization of glucose for the synthesis of milk components in the fed and starved lactating goat in vivo. Biochem. J. 186:301-308.

Cherepanov, G. G., A. Danfaer, and J. P. Cant. 2000. Simulation analysis of substrate utilization in the mammary gland of lactating cows. J. Dairy Res. 67:171-188.

Cornford, E. M., S. Hyman, and B. E. Swartz. 1994. The human brain GLUT1 glucose transporter: Ultrastructural localization to the blood-brain barrier endothelia. J. Cereb. Blood Flow Metab. 14:106-112.

Davis, S. R., R. J. Collier, J. P. McNamara, H. H. Head, W. J. Croom, and C. J. Wilcox. 1988. Effects of thyroxine and growth hormone treatment of dairy cows on mammary uptake of glucose, oxygen and other milk fat precursors. J. Anim. Sci. 66:80-89.

Delaquis, A. M., C. Malo, and T. D. Turner. 1993. $\mathrm{Na}^{+}$-independent glucose uptake by bovine mammary epithelial (MAC-T) cells. J. Dairy Sci. 76(Suppl. 1):188. (Abstr.)

Doege, H., A. Bocianski, H.-G. Joost, and A. Schürmann. 2000a. Activity and genomic organization of human glucose transporter 9 (GLUT9), a novel member of the family of sugar-transport facilitators predominantly expressed in brain and leucocytes. Biochem. J. 350:771-776.

Doege, H., A. Bocianski, A. Scheepers, H. Axer, J. Eckel, H.-G. Joost, and A. Schürmann. 2001. Characterization of human glucose transporter (GLUT) 11 (encoded by SLC2A11), a novel sugartransport facilitator specially expressed in heart and skeletal muscle. Biochem. J. 359:443-449.

Doege, H., A. Schürmann, G. Bahrenberg, A. Brauers, and H.-G. Joost. 2000b. GLUT8, a novel member of the sugar transport facilitator family with glucose transport activity. J. Biol. Chem. 275:16275-16280.

Duhlmeier, R., A. Hacker, A. Widdel, W. von Engelhardt, and H. P. Sallmann. 2005. Mechanisms of insulin-dependent glucose transport into porcine and bovine skeletal muscle. Am. J. Physiol. Regul. Integr. Comp. Physiol. 289:R187-R197.

Faulkner, A. 1999. Changes in plasma and milk concentrations of glucose and IGF-1 in response to exogenous growth hormone in lactating goats. J. Dairy Res. 66:207-214.

Faulkner, A., N. Chaiyabutr, M. Peaker, D. T. Carrick, and N. J. Kuhn. 1981. Metabolic significance of milk glucose. J. Dairy Res. 48:51-56.

Faulkner, A., and M. Peaker. 1987. Regulation of mammary glucose metabolism in lactation. Pages 535-562 in The Mammary Gland:
Development, Regulation, and Function. M. C. Neville and C. W. Daniel, ed. Plenum Press, New York, NY.

Fladeby, C., R. Skar, and G. Serck-Hanssen. 2003. Distinct regulation of glucose transport and GLUT1/GLUT3 transporters by glucose deprivation and IGF-I in chromaffin cells. Biochim. Biophys. Acta 1593:201-208.

Fukumoto, H., T. Kayano, J. B. Buse, Y. Edwards, P. F. Pilch, G. I. Bell, and S. Seino. 1989. Cloning and characterization of the major insulin-responsive glucose transporter expressed in human skeletal muscle and other insulin-responsive tissues. J. Biol. Chem. 264:7776-7779.

Fukumoto, H., S. Seino, H. Imura, Y. Seino, R. I. Eddy, Y. Fukushima, M. G. Byers, T. B. Shows, and G. I. Bell. 1988. Sequence, tissue distribution, and chromosomal localization of mRNA encoding a human glucose transporter-like protein. Proc. Natl. Acad. Sci. USA 85:5434-5438.

Haney, P. M. 2001. Localization of the GLUT1 glucose transporter to brefeldin A-sensitive vesicles of differentiated CIT3 mouse mammary epithelial cells. Cell Biol. Int. 25:277-288.

Hediger, M. A., M. J. Coady, T. S. Ikeda, and E. M. Wright. 1987. Expression cloning and cDNA sequencing of the $\mathrm{Na}^{+} /$glucose cotransporter. Nature 330:379-381.

Hocquette, J. F., F. Bornes, M. Balage, P. Ferre, J. Grizard, and M. Vermorel. 1995. Glucose-transporter (GLUT4) protein content in oxidative and glycolytic skeletal muscles from calf and goat. Biochem. J. 305:465-470.

Hocquette, J. F., C. Castiglia-Delavaud, B. Graulet, P. Ferre, B. Picard, and M. Vermorel. 1997. Weaning marginally affects glucose transporter (GLUT4) expression in calf muscles and adipose tissues. Br. J. Nutr. 78:251-271.

Hocquette, J. F., H. Sauerwein, Y. Higashiyama, B. Picard, and H. Abe. 2006. Prenatal developmental changes in glucose transporters, intermediary metabolism and hormonal receptors related to the IGF/insulin-glucose axis in the heart and adipose tissue of bovines. Reprod. Nutr. Dev. 46:257-272.

Holman, G. D., and I. V. Sandoval. 2001. Moving the insulin-regulated glucose transporter GLUT4 into and out of storage. Trends Cell Biol. 11:173-179.

Huhtanen, P., A. Vanhatalo, and T. Varvikko. 2002. Effects of abomasal infusions of histidine, glucose, and leucine on milk production and plasma metabolites of dairy cows fed grass silage diets. J. Dairy Sci. 85:204-216.

Hurtaud, C., S. Lemosquet, and H. Rulquin. 2000. Effect of graded duodenal infusions of glucose on yield and composition of milk from dairy cows. 2. Diets based on grass silage. J. Dairy Sci. 83:2952-2962.

Joost, H. G., and B. Thorens. 2001. The extended GLUT-family of sugar/polyol transport facilitators: Nomenclature, sequence characteristics, and potential function of its novel members (review). Mol. Membr. Biol. 18:247-256.

Kayano, T., C. F. Burant, H. Fukumoto, G. W. Gould, Y. S. Fan, R. L. Eddy, M. G. Byers, T. B. Shows, S. Seino, and G. I. Bell. 1990. Human facilitative glucose transporters-Isolation, function, characterization, and gene localization of cDNAs encoding an isoform (GLUT5) expressed in small intestine, kidney, muscle, and adipose tissue and an unusual glucose transporter pseudogene-like sequence (GLUT6). J. Biol. Chem. 265:13276-13282.

Kayano, T., H. Fukumoto, R. L. Eddy, Y. S. Fan, M. G. Byers, T. B. Shows, and G. I. Bell. 1988. Evidence for a family of human glucose transporter-like proteins. Sequence and gene localization of a protein expressed in fetal skeletal muscle and other tissues. J. Biol. Chem. 263:15245-15248.

Kim, C. H., T. G. Kim, J. J. Choung, and D. G. Chamberlain. 2001. Effects of intravenous infusion of amino acids and glucose on the yield and concentration of milk protein in dairy cows. J. Dairy Res. 68:27-34.

Komatsu, T., F. Itoh, S. Kushibiki, and K. Hodate. 2005. Changes in gene expression of glucose transporters in lactating and nonlactating cows. J. Anim. Sci. 83:557-564.

Kong, C. T., S. F. Yet, and J. E. Lever. 1993. Cloning and expression of a mammalian $\mathrm{Na}$ /amino acid cotransporter with sequence 
similarity to $\mathrm{Na}^{+} /$glucose cotranporters. J. Biol. Chem. 268:1509-1512.

Kronfeld, D. S. 1982. Major metabolic determinants of milk volume, mammary efficiency, and spontaneous ketosis in dairy cows. J. Dairy Sci. 65:2204-2212.

Li, Q., A. Manolescu, M. Ritzel, S. Yao, M. Slugoski, J. D. Young, X. Z. Chen, and C. I. Cheeseman. 2004. Cloning and functional characterization of the human GLUT7 isoform SLC2A7 from the small intestine. Am. J. Physiol. Gastrointest. Liver Physiol. 287:G236-G242.

Macheda, M. L., E. D. Williams, J. D. Best, M. E. Wlodek, and S. Rogers. 2003. Expression and localisation of GLUT1 and GLUT12 glucose transporters in the pregnant and lactating rat mammary gland. Cell Tissue Res. 311:91-97.

Madon, R. J., S. Martin, A. Davies, H. A. C. Fawcett, D. J. Flint, and S. A. Baldwin. 1990. Identification and characterization of glucose transport proteins in plasma membrane- and Golgi vesicle-enriched fractions prepared from lactating rat mammary gland. Biochem. J. 272:99-105.

McVie-Wylie, A. J., D. R. Lamson, and Y. T. Chen. 2001. Molecular cloning of a novel member of the GLUT family of transporters, SLC2a10 (GLUT10), localized on chromosome 20q13.1: A candidate gene for NIDDM susceptibility. Genomics 72:113-117.

Mepham, T. B., C. G. Prosser, C. Royle, L. M. Silvester, M. A. AlShaikh, and I. R. Fleet. 1990. The galactopoietic response to exogenous growth hormone in ruminants is associated with raised milk glucose concentration. J. Physiol. 427:21P.

Miller, P. J., K. A. Finucane, M. Hughes, and F.-Q. Zhao. 2005. Cloning and expression of bovine glucose transporter GLUT12. Mamm. Genome 16:873-883.

Mueckler, M., C. Caruso, S. A. Baldwin, M. Panico, I. Blench, H. R. Morris, W. J. Allard, G. E. Lienhard, and H. F. Lodish. 1985. Sequence and structure of human glucose transporter. Science 229:941-945.

Navarrete Santos, A., R. Augustin, G. Lazzari, C. Galli, J. M. Sreenan, and B. Fischer. 2000. The insulin-dependent glucose transporter isoform 4 is expressed in bovine blastocysts. Biochem. Biophys. Res. Commun. 271:753-760.

Nemeth, B. A., S. W. Y. Tsang, R. S. Geske, and P. M. Haney. 2000. Golgi targeting of the GLUT1 glucose transporter in lactating mouse mammary gland. Pediatr. Res. 47:444-450.

Neville, M. C., J. C. Allen, and C. Watters. 1983. The mechanisms of milk secretion. Pages 49-92 in Lactation: Physiology, Nutrition, and Breast-Feeding. M. C. Neville and M. R. Neifert, ed. Plenum, New York, NY.

Nishimoto, H., R. Matsutani, S. Yamamoto, T. Takahashi, K. G. Hayashi, A. Miyamoto, S. Hamano, and M. Tetsuka. 2006. Gene expression of glucose transporter (GLUT) 1,3 and 4 in bovine follicle and corpus luteum. J. Endocrinol. 188:111-119.

Nielsen, M. O., and K. Jakobsen. 1993. Changes in mammary glucose and protein uptake in relation to milk synthesis during lactation in high- and low-yielding goats. Comp. Biochem. Physiol. 106:359-365.

Nielsen, M. O., T. G. Madsen, and A. M. Hedeboe. 2001. Regulation of mammary glucose uptake in goats: Role of mammary gland supply, insulin, IGF-1 and synthetic capacity. J. Dairy Res. 68:337-349.

Pajor, A. M., and E. M. Wright. 1992. Cloning and functional expression of a mammalian $\mathrm{Na}+$ /nucleoside cotransporter. A member of the SGLT family. J. Biol. Chem. 267:3557-3560.

Phay, J. E., H. B. Hussain, and J. F. Moley. 2000. Cloning and expression analysis of a novel member of the facilitative glucose transporter family, SLC2A9 (GLUT9). Genomics 66:217-220.

Prosser, C. G. 1988. Mechanism of the decrease in hexose transport by mouse mammary epithelial cells caused by fasting. Biochem. J. 249:149-154.

Rogers, S., M. L. Macheda, S. E. Docherty, M. D. Carty, M. A. Henderson, W. C. Soeller, E. M. Gibbs, D. E. James, and J. D. Best. 2002. Identification of a novel glucose transporter-like proteinGLUT12. Am. J. Physiol. Endocrinol. Metab. 282:E733-E738.
Scott, R. A., D. E. Bauman, and J. H. Clark. 1976. Cellular gluconeogenesis by lactating bovine mammary tissue. J. Dairy Sci. 59:50-56.

Shennan, D. B., and M. Peaker. 2000. Transport of milk constituents by the mammary gland. Physiol. Rev. 80:925-951.

Sunehag, A. L., K. Louie, J. L. Bier, S. Tigas, and M. W. Haymond. 2002. Hexoneogenesis in the human breast during lactation. J. Clin. Endocrinol. Metab. 87:297-301.

Sunehag, A., S. Tigas, and M. W. Haymond. 2003. Contribution of plasma galactose and glucose to milk lactose synthesis during galactose ingestion. J. Clin. Endocrinol. Metab. 88:225-229.

Takata, K., K. Fujikura, M. Suzuki, T. Suzuki, and H. Hirano. 1997. GLUT1 glucose transporter in the lactating mammary gland in the rat. Acta Histochem. Cytochem. 30:623-628.

Threadgold, L. C., H. G. Coore, and N. J. Kuhn. 1982. Monosaccharide transport into lactating-rat mammary gland acini. Biochem. J. 204:493-501.

Threadgold, L. C., and N. J. Kuhn. 1979. Glucose 6-phosphate hydrolysis by lactating rat mammary gland. Int. J. Biochem. 10:683685

Uldry, M., M. Ibberson, B. Riederer, J. Y. Chatton, J. D. Horisberger, and B. Thorens. 2001. Identification of a novel $\mathrm{H}^{+}$-myoinositol symporter expressed predominantly in the brain. EMBO J. 20:4467-4477.

Watson, R. T., M. Kanzaki, and J. E. Pessin. 2004. Regulated membrane trafficking of the insulin-responsive glucose transporter 4 in adipocytes. Endocr. Rev. 25:177-204.

Watson, R. T., and J. E. Pessin. 2006. Bridging the GAP between insulin signaling and GLUT4 translocation. Trends Biochem. Sci. 31:215-222.

Wells, R. G., Y. Kanai, A. M. Pajor, E. Yurk, E. M. Wright, and H. A. Hediger. 1992. The cloning of a human kidney cDNA with similarity to the sodium/glucose cotransporter. Am. J. Physiol. Renal Fluid Electrolyte Physiol. 263:F459-F465.

Widdas, W. F. 1988. Old and new concepts of the membrane transport for glucose in cells. Biochim. Biophys. Acta 947:385-404.

Wood, I. S., and P. Trayhurn. 2003. Glucose transporters (GLUT and SGLT): Expanded families of sugar transport proteins. Br. J. Nutr. 89:3-9.

Wright, E. M. 2001. Renal $\mathrm{Na}^{+}$-glucose cotransporters. Am. J. Physiol. Renal Physiol. 280:F10-F18.

Wright, E. M., and E. Turk. 2004. The sodium/glucose cotransport family SLC5. Pflugers Arch. 447:510-518.

Wu, X., W. Li, V. Sharma, A. Godzik, and H. H. Freeze. 2002. Cloning and characterization of glucose transporter 11, a novel sugar transporter that is alternatively spliced in various tissues. Mol. Genet. Metab. 76:37-45.

Xiao, C., and J. P. Cant. 2003. Glucose transporter in bovine mammary epithelial cells is an asymmetric carrier that exhibits cooperativity and trans-stimulation. Am. J. Physiol. Cell Physiol. 285:C1226-C1234.

Xiao, C., V. M. Quinton, and J. P. Cant. 2004. Description of glucose transport in isolated bovine mammary epithelial cells by a 3 compartment model. Am. J. Physiol. Cell Physiol. 286:C792C797.

Zhao, F.-Q., W. T. Dixon, and J. J. Kennelly. 1996a. Localization and gene expression of glucose transporters in bovine mammary gland. Comp. Biochem. Physiol. 115B:127-134.

Zhao, F.-Q., D. R. Glimm, and J. J. Kennelly. 1993. Distribution of mammalian facilitative glucose transporter messenger RNA in bovine tissues. Int. J. Biochem. 25:1897-1903.

Zhao, F.-Q., T. B. McFadden, E. H. Wall, B. Dong, and Y.-C. Zheng. 2005a. Cloning and expression of bovine sodium/glucose cotransporter SGLT2. J. Dairy Sci. 88:2738-2748.

Zhao, F.-Q., P. J. Miller, E. H. Wall, Y.-C. Zheng, B. Dong, M. C. Neville, and T. B. McFadden. 2004. Bovine glucose transporter GLUT8: Cloning, expression, and developmental regulation in mammary gland. Biochim. Biophys. Acta 1680:103-113.

Zhao, F.-Q., M. W. Moseley, H. A. Tucker, and J. J. Kennelly. 1996b. Regulation of glucose transporter gene expression in mammary gland, muscle and fat of lactating cows by administration of bovine 
growth hormone and bovine growth hormone-releasing factor. J. Anim. Sci. 74:183-189.

Zhao, F.-Q., M. W. Moseley, H. A. Tucker, and J. J. Kennelly. 1996c. Regulation of glucose transporter gene expression in liver and kidney of lactating cows by administration of bovine growth hormone and bovine growth hormone-releasing factor. J. Dairy Sci. 79:1537-1542.

Zhao, F.-Q., E. R. Okine, C. I. Cheeseman, S. P. Shirazi-Beechey, and J. J. Kennelly. 1998. Gene expression of $\mathrm{Na}^{+} /$glucose cotrans- porter in lactating bovine gastrointestinal tract. J. Anim. Sci. 76:2921-2929.

Zhao, F.-Q., E. R. Okine, and J. J. Kennelly. 1999. Glucose transporter gene expression in bovine mammary gland. J. Anim. Sci. 77:2517-2522.

Zhao, F.-Q., Y.-C. Zheng, E. H. Wall, and T. B. McFadden. 2005b. Cloning and expression of bovine sodium/glucose cotransporters. J. Dairy Sci. 88:182-194. 